\title{
Hypercoagulability: Another Potential Mechanism of Obstructive Sleep Apnea-Related Cardiovascular Disease?
}

\author{
Nabil M. Al Lawati $\cdot$ Najib T. Ayas
}

Received: 4 March 2008/Accepted: 19 March 2008/Published online: 22 April 2008

(C) Springer Science+Business Media, LLC 2008

Obstructive sleep apnea (OSA) is a common disease with substantial health and economic impact [1-3]. During sleep, the upper airway collapses repeatedly leading to sleep fragmentation and oxyhemoglobin desaturation. Furthermore, there are compelling epidemiologic data implicating OSA in the development of myocardial infarction and cerebrovascular events. For example, Marin et al. [4] published data from a cohort of patients with varying degrees of sleep-disordered breathing (snorers, mild-severe OSA) and healthy participants who were followed for a mean of 10 years. Patients with severe untreated OSA had a much greater risk of developing fatal (odds ratio $[\mathrm{OR}]=2.87,95 \% \mathrm{CI}=1.17-2.51$ ) and nonfatal cardiovascular disease $(C V D) \quad(O R=3.17,95 \%$ $\mathrm{CI}=1.12-7.51) \quad$ compared to healthy controls after adjustment for potential confounding factors. Patients with OSA who were treated with CPAP did not have an increased rate of events $(\mathrm{OR}=1.05,95 \% \mathrm{CI}=0.39-2.21$ and $\mathrm{OR}=1.42,95 \% \mathrm{CI}=0.52-3.4$, respectively) compared to healthy controls, suggesting that substantial benefits may be seen with therapy.

In another study, Peker et al. [5] prospectively followed 182 middle-aged men with no hypertension or CVD at baseline who were referred for a sleep study. Incident CVD (i.e., hypertension, coronary artery disease, stroke, myocardial infarction, arrhythmias) over 7 years occurred in $37 \%$ of patients with OSA compared to $6.6 \%$ in those

N. M. Al Lawati · N. T. Ayas ( $₫)$

Sleep Disorders Program and Respiratory Division,

University British Columbia, Vancouver, BC, Canada

e-mail: Najib.Ayas@vch.ca

N. T. Ayas

Respiratory Division, Diamond Centre, 7th Floor,

2775 Laurel Street, Vancouver, BC, Canada V5Z 1M9 without OSA. In a study from the Sleep Heart Health Cohort, the prevalence of CVD, including myocardial infarction, angina, coronary revascularization, heart failure, and stroke was 1.42 times greater in patients with OSA (apnea-hypopnea index $[\mathrm{AHI}]>11$ events/h) compared to those without OSA (AHI $=0-1.3$ events/h) after controlling for potential confounders [6].

The pathophysiology of CVD secondary to OSA is complex. Patients with OSA have sustained activation of the sympathetic nervous system, systemic inflammation with increased levels of inflammatory mediators such as $\mathrm{C}$ reactive protein and IL-6 [7], glucose intolerance/insulin resistance [8], other metabolic derangements [9], and endothelial dysfunction [10]. Many of these physiologic/ biochemical abnormalities are implicated in the pathogenesis of CVD and represent potential pathogenic mechanisms.

Another potential mechanism is blood hypercoagulability. Data from the Framingham cohort has shown that each standard deviation increment in the level of the procoagulant molecule fibrinogen was associated with a $20 \%$ increased risk of coronary heart disease for men and $30 \%$ for women. A $10 \%$ increased risk of stroke was noted in both sexes. [11]. In a meta-analysis of 18 studies by Danesh et al. [12], higher fibrinogen was associated with a relative risk of $1.8(95 \%$ $\mathrm{CI}=1.6-2.0)$ for coronary heart disease.

Patients with OSA suffer from increased hypercoagulability. Blood viscosity and hematocrit are greater in patients with OSA compared to controls [13, 14]. Patients with OSA also suffer from increased platelet activity [15, 16]. Serum levels of procoagulant molecules such as fibrinogen [17], activated clotting factor VII (FVIIa), XIIa, and thrombin/antithrombin III complexes are increased in patients with OSA [18].

Another potential contributing mechanism is decreased fibrinolytic activity, as reflected by higher levels of 
plasminogen activator inhibitor-1 (PAI-1). In a large prospective cohort study of 10,500 male participants, the odds ratio for CVD per standard deviation increase in PAI-1 was 1.38 ( $\mathrm{CI}=1.27-1.49)$ [19]. Kohler et al. [20] have elegantly reviewed potential mechanisms by which PAI-1 may contribute to an increased risk of CVD.

Zamarrón et al. [21] studied 96 male subjects and measured levels of PAI-1. Levels of PAI-1 were greater in patients with OSA and hypertension $(105.0 \mathrm{ng} / \mathrm{ml})$ than in the OSA-only group $(57.0 \mathrm{ng} / \mathrm{ml}, p<0.001)$. Both groups had higher PAI-1 levels than controls $(39.7 \mathrm{ng} / \mathrm{ml}$, $p<0.001)$. These findings are consistent with other investigators. Von Känel et al. [22] have shown that PAI-1 levels are significantly correlated with mean oxygen saturation and AHI. Similarly, Rångemark et al. [23] demonstrated greater PAI-1 levels in patients with OSA, with a trend toward higher values in those with lower minimum overnight oxygen saturation. The mechanisms leading to decreased fibrinolysis in OSA are not clear. It is possible that hypoxia and repeated increase in sympathetic nervous system activity may lead to increased production of PAI-1 [24]. In this regard, PAI-1 levels are increased in other conditions associated with oxidative stress and tissue hypoxia [25].

Although we must be cautious given the small sample size and cross-sectional nature, the study by Zamarrón et al. [21] further highlights the potential role of hypercoagulability as a possible mechanistic pathway in the development of cardiovascular complications in patients with OSA. Future prospective epidemiologic studies linking PAI-1 levels to important clinical events (such as stroke or myocardial infarction) in OSA patients and examining the impact of OSA therapy on PAI-1 levels would be useful to understanding whether impaired fibrinolysis is truly an important cardiovascular biomarker in OSA.

\section{References}

1. Young T, Palta M, Dempsey J, Skatrud J, Weber S, Badr S (1993) The occurrence of sleep-disordered breathing among middle-aged adults. N Engl J Med 328(17):1230-1235

2. AlGhanim N, Comondore VR, Fleetham J, Marra CA, Ayas NT (2008) The economic impact of obstructive sleep apnea. Lung 186(1):7-12

3. Mermigkis C, Chapman J, Golish J, Mermigkis D, Budur K, Kopanakis A, Polychronopoulos V, Burgess R, Foldvary-Schaefer N (2007) Sleep-related breathing disorders in patients with idiopathic pulmonary fibrosis. Lung 185(3):173-178

4. Marin JM, Carrizo SJ, Vincente E, Agusti AG (2005) Long-term cardiovascular outcomes in men with obstructive sleep apnoeahypopnea with or without treatment with continuous positive airway pressure: an observational study. Lancet 365:1046-1053

5. Peker Y, Hedner J, Norum J, Kraiczi H, Carlson J (2002) Increased incidence of cardiovascular disease in middle-aged men with obstructive sleep apnea: a 7-year follow-up. Am J Respir Crit Care Med 166(2):159-165
6. Shahar E, Whitney CW, Redline S, Lee ET, Newman AB, Javier Nieto F, O'Connor GT, Boland LL, Schwartz JE, Samet JM (2001) Sleep-disordered breathing and cardiovascular disease: cross-sectional results of the Sleep Heart Health Study. Am J Respir Crit Care Med 163(1):19-25

7. Shamsuzzaman AS, Winnicki M, Lanfranchi P, Wolk R, Kara T, Accurso V, Somers VK (2002) Elevated C-reactive protein in patients with obstructive sleep apnea. Circulation 105(21):2462-2464

8. Tasali E, Ip MS (2008) Obstructive sleep apnea and metabolic syndrome: alterations in glucose metabolism and inflammation. Proc Am Thorac Soc 5:207-217

9. Ursavas A, Karadag M, Ilcol YO, Ercan I, Burgazlioglu B, Coskun F, Gozu RO (2007) Low level of IGF-1 in obesity may be related to obstructive sleep apnea syndrome. Lung 185(5):309-314

10. Budhiraja R, Parthasarathy S, Quan SF (2007) Endothelial dysfunction in obstructive sleep apnea. J Clin Sleep Med 3(4):409-415

11. Kannel WB (2005) Overview of hemostatic factors involved in atherosclerotic cardiovascular disease. Lipids 40(12):1215-1220

12. Danesh J, Collins R, Appleby P, Peto R (1998) Association of fibrinogen, C-reactive protein, albumin or leukocyte count with coronary heart disease; meta-analyses of prospective studies. JAMA 279:1477-1482

13. Nobili L, Schiavi G, Bozano E, De Carli F, Ferrillo F, Nobili F (2000) Morning increase of whole blood viscosity in obstructive sleep apnea syndrome. Clin Hemorheol Microcirc 22:21-27

14. Hoffstein V, Herridge M, Mateika S, Redline S, Strohl KP (1994) Hematocrit levels in sleep apnea. Chest 106:787-791

15. Geiser T, Buck F, Meyer BJ, Bassetti C, Haeberli A, Gugger M (2002) In vivo platelet activation is increased during sleep in patients with obstructive sleep apnea syndrome. Respiration 69:229-234

16. Hui DS, Ko FW, Fok JP, Chan MC, Li TS, Tomlinson B, Cheng $\mathrm{G}$ (2004) The effects of nasal continuous positive airway pressure on platelet activation in obstructive sleep apnea syndrome. Chest 125:1768-1775

17. Wessendorf TE, Thilmann AF, Wang YM, Schreiber A, Konietzko N, Teschler H (2000) Fibrinogen levels and obstructive sleep apnea in ischemic stroke. Am J Respir Crit Care Med 162:2039-2042

18. Robinson GV, Pepperell JC, Segal HC, Davies RJ, Stradling JR (2004) Circulating cardiovascular risk factors in obstructive sleep apnoea: data from randomised controlled trials. Thorax 59:777-782

19. Scarabin PY, Aillaud MF, Amouyel P, Evans A, Luc G, Ferrières J, Arveiler D, Juhan-Vague I (1998) Association of fibrinogen, factor VII and PAI-1 with baseline findings among 10,500 male participants in a prospective study of myocardial infarction-The PRIME Study. Prospective EpidemiologicalStudy of Myocardial Infarction. Thromb Haemost 80:749-756

20. Kohler HP, Grant PJ (2000) plasminogen-activator inhibitor type 1 and coronary artery disease. N Engl J Med 342:1792-1801

21. Zamarrón C, Ricoy J, Riveiro A, Gude F (2008) Plasminogen activator inhibitor-1 in obstructive sleep apnea patients with and without hypertension. Lung 186. doi:10.1007/s00408-008-9076-8

22. Von Kanel R, Loredo JS, Ancoli-Israel S, Mills PJ, Natarajan L, Dimsdale JE (2007) Association between polysomnographic measures of disrupted sleep and prothrombotic factors. Chest 131:733-739

23. Rangemark C, Hedner JA, Carlson JT, Gleerup G, Winther K (1995) Platelet function and fibrinolytic activity in hypertensive and normotensive sleep apnea patients. Sleep 18:188-194

24. von Kanel R, Dimsdale JE (2003) Hemostatic alterations in patients with obstructive sleep apnea and the implications for cardiovascular disease. Chest 124:1956-1967

25. Dimova EY, Samoylenko A, Kietzmann T (2004) Oxidative stress and hypoxia: implications for plasminogen activator inhibitor-1 expression. Antioxid Redox Signal 6(4):777-791 